\title{
Suicide risk among Thai illicit drug users with and without mental/alcohol use disorders
}

\author{
This article was published in the following Dove Press journal: \\ Neuropsychiatric Disease and Treatment \\ 13 March 2014 \\ Number of times this article has been viewed
}

Phunnapa

Kittirattanapaiboon'

Sirijit Suttajit ${ }^{2}$

Boonsiri Junsirimongkol'

Surinporn Likhitsathian ${ }^{2}$

Manit Srisurapanont ${ }^{2}$

'Department of Mental Health, Ministry of Public Health, Nonthaburi, Thailand; ${ }^{2}$ Department of Psychiatry, Faculty of Medicine, Chiang Mai University, Chiang Mai, Thailand

Correspondence: Phunnapa

Kittirattanapaiboon

Bureau of Mental Health Service

Administration, Department of Mental

Health, Ministry of Public Health,

Tivanon Road, Muang,

Nonthaburi, I 1000 Thailand

Tel +66 21495539

Fax +6621495538

Email phunnapa@hotmail.com
Background: It is not yet known if the increased risk of suicide in substance abusers is caused by the causal and/or coexisting relationship between substance use and psychiatric disorders. This study was designed to estimate the suicide risk among individuals with illicit drug use alone, illicit drug users with mental disorders, and illicit drug users with alcohol use disorders.

Methods: Subjects were participants of the 2008 Thai National Mental Health Survey. They were asked for their illicit drug use in the past year. The Mini International Neuropsychiatric Interview (MINI), current suicidality (1 month prior to assessment), mood episodes, anxiety disorders, psychotic disorders, and alcohol use disorders were used for assessing mental/alcohol use disorders. A score of 1 or more for the MINI-Suicidality module was defined as the presence of suicide risk.

Results: Of the total 17,140 respondents, 537 currently used illicit drugs, while 1,194 respondents had a suicide risk. Common illicit drugs were kratom (59\%) and (meth)amphetamine (24\%). Compared with 16,603 Thais without illicit drug use, the illicit drug users with or without mental/alcohol use disorders $(n=537)$ had an increased risk of suicide (adjusted odds ratio $[\mathrm{OR}], 95 \%$ confidence interval $[\mathrm{CI}]=2.09,1.55-2.81$ ). While those who used illicit drugs alone (no mental/alcohol use disorder) $(n=348)$ had no increased risk of suicide (adjusted OR, $95 \% \mathrm{CI}=1.04,0.66-1.65)$, the illicit drug users with mental or alcohol use disorders $(\mathrm{n}=27$ and $\mathrm{n}=162$, respectively) had significantly increased risk of suicide (adjusted ORs, $95 \%$ CIs $=14.06$, 6.50-30.3 and 3.14, 1.98-4.99, respectively).

Conclusion: A key limitation of this study was the combined suicidal behaviors as a suicidality risk. Mental or alcohol use disorders found in this population actually increased the suicide risk. These findings support the coexisting relationship that mental and alcohol use disorders play a vital role in increasing the suicide risk in illicit drug users.

Keywords: drug use, psychiatric disorder, alcoholism

\section{Introduction}

Suicidal behavior (suicide idea, plan, and attempt) is an issue of concern among people who misuse alcohol and other substances. Committed suicide is a leading cause of premature death among individuals with alcohol, tobacco, and illicit drug use. ${ }^{1}$ Substance use disorders (SUDs) are also one of the strongest predictors of suicide in people living in developing countries. ${ }^{2}$

Several lines of evidence suggest that individuals with SUDs have an increased risk of suicide. In clinical settings, a meta-analysis found that the standardized mortality ratio for substance abuse (mixed) was 19.2, which was comparable to that of major depressive disorders (standardized mortality ratio $=20.4$ ). ${ }^{3}$ Compared with the general population, people with SUDs had a 3.9- to 5.8-fold increased risk of suicide. ${ }^{4}$ Another large 
multicountry epidemiological study found that SUDs were associated with a 2.8- to 4.6-fold increase of suicide risk. ${ }^{5}$ Some findings suggest that substance use and suicidality are associated risk behaviors. ${ }^{6}$ In addition, the more severe patterns of cocaine, sedative, or benzodiazepine use may be linked to the greater likelihood of suicide attempts. ${ }^{7}$

Mental disorders are a common comorbidity of SUDs and may raise the suicidal risk in an additive way. ${ }^{8,9}$ In the US Epidemiologic Catchment Area Program, the prevalence of mental disorders in people with SUDs (53\%) was higher than that of the general population $(22.5 \%) .{ }^{10}$ Compared with German adults, the presence of SUDs in major depressive patients was linked to a 14-fold increased risk of suicide attempts. ${ }^{11}$ A case-control study in East Taiwan found that major depression was the most common comorbidity in suicides with SUDs (43\%). ${ }^{12}$ Some experts hypothesize that the comorbidity of substance use and mental disorders such as depressive disorder heightens the suicidal risk through impulsivity, hostility, and aggression. ${ }^{13}$

Little is known about the suicide risk among Asians with SUDs and mental comorbidity. A study found that SUDs were associated with a 1.8-fold increased risk of suicide risk in Chinese people with mental disorders. ${ }^{14}$ In a Taiwanese study, apart from the suicide risk affected by SUDs comorbid with major depression, the investigators did not present such risk in people with SUDs and other mental disorder comorbidities. $^{12}$

Borges and Loera describe the relationship between substance use and suicidal behavior as causal and coexisting due to a third factor. ${ }^{15}$ For the causal relationship, substance use plays a vital role in increasing the likelihood of suicidal behavior regardless of other known risk factors. The coexisting relationship model considers substance use as a marker of some personality proneness to suicide or as a consequence of other known risk factors, such as depression. While the association between suicidal and substance use behaviors is relatively complex, none of the aforementioned findings can determine if the increased risk of suicide in substance abusers is due to a causal and/or coexisting relationship.

In 2008, the Department of Mental Health, Ministry of Public Health, Thailand conducted a National Mental Health Survey (Thai NMH Survey). ${ }^{16,17}$ A major aim of this survey was to determine the prevalence of mental disorders in Thai people living in communities. By using Thais without illicit drug use as a reference group, this study aimed at estimating the suicide risk among individuals with illicit drug use alone, illicit drug use with mental disorders, and illicit drug use with alcohol use disorders.

\section{Methods}

The protocol of the 2008 Thai NMH Survey was approved by the Ethics Committee of the Department of Mental Health, Ministry of Public Health. Each participant had given written informed consent before the participation.

\section{Sample}

The target population of the 2008 Thai NMH Survey was the civilian noninstitutionalized people aged between 15 and 59 years residing in households. The survey applied a stratified three-stage random sampling method, which covered all five geographical areas of the country, including Bangkok (the capital), Central, Northern, Northeastern, and Southern regions. Randomly selected areas were 76 urban districts in Bangkok and 76 urban/76 rural districts in each of the other four regions. Stratified by sex and age groups, this survey interviewed a random sample of 17,140 Thai people living in communities. To reflect a nationally representative data design, sex and response weights were applied on the data obtained from this sample. Other details can be seen in recent articles. ${ }^{17,18}$

\section{Assessment}

Between June and August 2008, the survey staff conducted face-to-face interviews using the Mini International Neuropsychiatric Interview (MINI) version 5.0 (July 1, 2005). The MINI had been translated into Thai and its validity tested against board-certified psychiatrists interviews. In a clinical sample of 177 patients with various mental disorders, including 30 patients with drug and alcohol use disorders, the sensitivity and specificity of all MINI-Thai modules were $0.33-0.98$ and $0.92-1.00$, respectively. ${ }^{19}$ All interviewers of this survey were mental health professionals, including psychiatric nurses, psychiatric nursing assistants, psychologists, and social workers. Each of them was well trained for the use of MINI-Thai.

\section{Suicide risk}

The MINI-Suicidality module has nine questions relevant to suicidal behavior. Each respondent was asked for a yes/no response to each question. Those questions included 1) intentional accident, 2) death wish, 3) self-harm wish, 4) suicide idea, 5) suicide plan, 6) suicide plan with preparation, 7) deliberate injuring of oneself, 8) suicide attempt in the past month, and 9) lifetime suicide attempts. Except the question inquiring about lifetime suicide attempts, all other questions were relevant to suicidal behaviors 1 month prior to assessment. As proposed by the instrument 
developers, the first question of intentional accident has no score. The response to this question, therefore, was not taken into account. A respondent giving a "yes" response to any of the rest of the questions was defined as an individual with suicide risk.

\section{Mental/alcohol use disorders}

The survey used the following modules of the MINI to assess mental disorders in each respondent: major depressive episode, dysthymia, (hypo)manic episode, generalized anxiety disorder, panic disorder, agoraphobia, posttraumatic stress disorder, and psychotic disorders. Alcohol abuse and dependence were combined as alcohol use disorders. Because the MINI barely assesses lifetime disorders, only the current ones were considered.

\section{Illicit drug use}

Each respondent was interviewed based on his or her illicit drug use during the year prior to assessment. Each of the common illicit drugs in Thailand was raised for a response of use/not use. Those included kratom leaves (Mitragyna speciosa Korth), (meth)amphetamine, cannabis, inhalant, ecstasy, opium, heroin, d-lysergic acid diethylamide (LSD), secobarbital sodium, cocaine, ketamine, morphine, and phencyclidine.

\section{Data analysis}

The sociodemographic characteristics that might affect the suicide risk in the general population were determined. We calculated an odds ratio (OR) with $95 \%$ confidence interval (CI) for each characteristic. Variables significantly associated with suicide risk $(P<0.05)$ were included as potential confounders. Odds ratios and 95\% CIs were calculated using logistic regression with and without adjustment for the association between illicit drug use and suicide risk, as well as the association between mental/alcohol use disorders and suicide risk in the illicit drug users. We used SPSS version 17 software (IBM Corporation, Armonk, NY, USA) for the statistical analyses.

\section{Results}

\section{Sociodemographic characteristics}

The prevalence of mental disorders was $15.1 \%$. Of the total 17,140 respondents, 537 (3.1\%) (489 men and 48 women) were current illicit drug users with a mean age (standard deviation) of 34.5 (12.3) years. Illicit drugs abused by these users (n,\%) were kratom ( $\mathrm{n}=317,59 \%)$, (meth)amphetamine $(n=129,24 \%)$, cannabis $(n=105,19.6 \%)$, inhalants $(n=41,7.6 \%)$, ecstasy $(n=17,3.2 \%)$, opium $(n=13,2.4 \%)$, heroin $(n=8,1.5 \%)$, LSD $(n=7,1.3 \%)$, secobarbital sodium $(n=7,1.3 \%)$, cocaine $(n=5,0.9 \%)$, and ketamine/morphine/ phencyclidine $(n=5,0.9 \%)$.

Of the total sample, 1,194 people $(7.0 \% ; 427$ men and 767 women), with a mean age (standard deviation) of 38.4 (13.0) years, currently had a suicide risk. Suicidal behaviors included death wish $(\mathrm{n}=832,69.7 \%)$, self-harm wish ( $n=178,14.9 \%)$, suicide idea $(n=284,23.8 \%)$, suicide plan $(n=65,5.4 \%)$, suicide plan with preparation $(n=43$, $3.6 \%)$, deliberate injuring of oneself $(n=96,8.0 \%)$, suicide attempt in the past month ( $\mathrm{n}=56,4.7 \%)$, and lifetime suicide attempts $(n=454,38 \%)$.

\section{Correlations of sociodemographic characteristics and suicide risk}

Table 1 shows the sociodemographic characteristics of 17,140 respondents, segregated into those who had and did not have a suicide risk. The sociodemographic factors significantly associated with a suicide risk included sex $(P<0.001)$, age $(P=0.014)$, marital status $(P<0.001)$, region $(P<0.001)$, and educational level $(P<0.001)$. These dependent variables were controlled in estimating the adjusted ORs (95\% CIs) for the suicide risk in illicit drug users.

\section{Suicide risk in illicit drug users}

Thais without illicit drug use $(n=16,603)$ were the reference group for all comparisons. Of 537 illicit drug users, 27 had mental disorders, and 162 had alcohol use disorders. The 27 participants with mental disorders also included 13 illicit drug users with comorbid mental and alcohol use disorders. For the whole group, the illicit drug users with or without mental/alcohol use disorders $(n=537)$ had an increased risk of suicide (adjusted OR, 95\% CI =2.09, 1.55-2.81, $P<0.001$ ) (Table 2). While those who used illicit drugs alone (no mental/ alcohol use disorder; $n=348$ ) had no increased risk of suicide (adjusted OR, 95\% CI =1.04, 0.66-1.65, $P=0.869$ ), the illicit drug users with mental or alcohol use disorders $(n=27$ and $\mathrm{n}=162$, respectively) had a significantly increased risk of suicide (adjusted ORs, 95\% CIs $=14.06,6.50-30.3, P<0.001$ and 3.14, 1.98-4.99, $P<0.001$, respectively).

\section{Discussion}

This was a community-based epidemiological study in Southeast Asia comparing the suicide risk between illicit drug users and those without illicit drug use. Although the illicit drug users as a group had an increased risk of suicide, such an increased risk was not found in drug users who had 
Table I Sociodemographic characteristics and their correlations with suicide risk in 17, I40 Thais living in the community

\begin{tabular}{|c|c|c|c|c|}
\hline \multirow[t]{3}{*}{ Sociodemographic characteristic } & \multicolumn{2}{|l|}{ Suicide risk } & \multirow[t]{3}{*}{ Odds ratio $(95 \% \mathrm{Cl})$} & \multirow[t]{3}{*}{$P$-value } \\
\hline & Yes $(N=I, 194)$ & No $(N=15,946)$ & & \\
\hline & n (\%) & n (\%) & & \\
\hline \multicolumn{5}{|l|}{ Sex } \\
\hline Male & $427(35.8)$ & $8,069(50.6)$ & I (ref) & $<0.001$ \\
\hline Female & $767(64.2)$ & $7,877(49.4)$ & $1.84(1.64-2.08)$ & \\
\hline \multicolumn{5}{|l|}{ Age (years) } \\
\hline $15-29$ & $348(29.1)$ & $5,128(32.2)$ & I (ref) & 0.014 \\
\hline $30-44$ & $395(33.1)$ & $5,426(34.0)$ & $1.07(0.92-1.25)$ & \\
\hline $45-59$ & $45 \mathrm{I}(37.8)$ & $5,392(33.8)$ & $1.23(1.07-1.43)$ & \\
\hline \multicolumn{5}{|l|}{ Marital status } \\
\hline Widowed, separated, or divorced & $176(14.7)$ & $\mathrm{I}, 233(7.7)$ & I (ref) & $<0.001$ \\
\hline Single & $284(23.8)$ & $4,231(26.5)$ & $1.04(0.91-1.20)$ & \\
\hline Married & $734(61.5)$ & $10,482(65.7)$ & $2.13(1.74-2.59)$ & \\
\hline \multicolumn{5}{|l|}{ Region } \\
\hline Central & $194(16.2)$ & $3,618(22.7)$ & I (ref) & $<0.001$ \\
\hline Bangkok & $165(13.8)$ & $1,721(10.8)$ & $1.79(1.44-2.22)$ & \\
\hline Northwest & $250(20.9)$ & $3,556(22.3)$ & $1.31(1.08-1.59)$ & \\
\hline North & $349(29.2)$ & $3,452(21.6)$ & $1.89(1.57-2.26)$ & \\
\hline South & $236(19.8)$ & $3,599(22.6)$ & $1.22(1.01-1.49)$ & \\
\hline \multicolumn{5}{|l|}{ Education level } \\
\hline College or more & $45(3.8)$ & $877(5.5)$ & I (ref) & $<0.001$ \\
\hline High school & $458(38.4)$ & $6,839(42.3)$ & $1.33(0.97-1.8 I)$ & \\
\hline Less than high school & 69I (57.9) & $8,330(52.2)$ & $1.62(1.19-2.20)$ & \\
\hline
\end{tabular}

Abbreviations: $\mathrm{Cl}$, confidence interval; $\mathrm{n}$, number; $\mathrm{N}$, total number in group; Ref, reference.

no mental/alcohol use disorder. For the illicit drug users with mental/alcohol use disorders, we found that mental or alcohol use disorders were associated with a 14.06- or 3.86fold increased risk of suicide, respectively. Although it was interesting to know whether the comorbidity of mental and alcohol use disorders further increased the suicide risk, we declined to analyze the data of this too-small sample size $(n=13)$. However, these present findings were satisfactory enough to support the coexisting relationship that mental or alcohol use disorders play a vital role in increasing the suicide risk in illicit drug users.

Similar to previous studies, the present research found an increased risk of suicide among Thai illicit drug users. The present risk (2.09-fold) is relatively smaller than those in the US and multicountry studies (2.8- to 5.8 -fold). ${ }^{4,5}$ For comorbid mental disorders, previous studies found that the suicide risk among people with comorbid major depression and SUDs was higher than that of those with major depression alone. ${ }^{11,12}$ However, these later studies did not compare the suicide risk between SUDs alone and SUDs comorbid with mental disorders.

To our knowledge, this is the first epidemiological study examining the suicide risk in illicit drug users with and without mental/alcohol use disorders. The present finding suggested that the risk was higher in illicit drug users with mental disorders and was in concordance with the previous ones, which pointed out the much higher risk among major depressive patients with SUD comorbidity. ${ }^{11}$ The new

Table 2 Suicide risk in Thai illicit drug users compared with those without illicit drug use $(\mathrm{N}=16,603)$

\begin{tabular}{|c|c|c|c|c|c|}
\hline \multirow[t]{2}{*}{ Independent factors } & \multicolumn{2}{|l|}{ Suicide risk } & \multirow{2}{*}{$\begin{array}{l}\text { Odds ratio } \\
(95 \% \mathrm{Cl})\end{array}$} & \multirow{2}{*}{$\begin{array}{l}\text { Adjusted odds ratio } \\
(95 \% \mathrm{Cl})\end{array}$} & \multirow[t]{2}{*}{$P$-value } \\
\hline & $\begin{array}{l}\text { Yes }(N=1,194) \\
\text { n (\%) }\end{array}$ & $\begin{array}{l}\text { No }(N=15,946) \\
n(\%)\end{array}$ & & & \\
\hline Illicit drug use $(\mathrm{N}=537)$ & $54(4.5 \%)$ & $483(3.0 \%)$ & $1.52(1.14-2.02)$ & $2.09(1.55-2.8 I)$ & $<0.001$ \\
\hline Illicit drug use alone $(n=348)$ & $20(1.7 \%)$ & $328(2.1 \%)$ & $0.8 \mathrm{I}(0.5 \mathrm{I}-1.28)$ & $1.04(0.66-1.65)$ & 0.869 \\
\hline $\begin{array}{l}\text { Illicit drug use with mental } \\
\text { disorders }^{a}(n=27)\end{array}$ & $12(1.0 \%)$ & $15(0.1 \%)$ & 10.78 (5.04-23.09) & $14.06(6.50-30.38)$ & $<0.001$ \\
\hline $\begin{array}{l}\text { Illicit drug use with alcohol use } \\
\text { disorders }^{b}(n=162)\end{array}$ & $22(1.8 \%)$ & 140 (0.9\%) & $2.12(1.35-3.34)$ & $3.14(1.98-4.99)$ & $<0.001$ \\
\hline
\end{tabular}

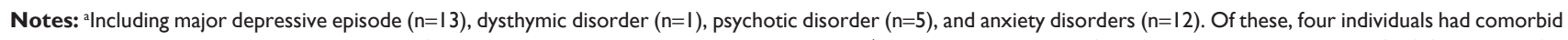

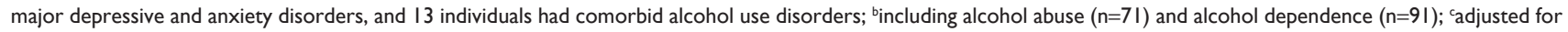
sex, age, marital status, region, and educational level.

Abbreviations: $\mathrm{Cl}$, confidence interval; $\mathrm{n}$, number; $\mathrm{N}$, total number in group. 
findings obtained from this study were that both mental and alcohol use disorders increased the suicide risk among illicit drug users.

The present study had some limitations. First, its sample size was smaller than those of previous epidemiological studies. Because this study focused on current drug use and current mental/alcohol use disorders (ie, illicit drug use, suicide risk, mental disorders, alcohol use disorders), only small numbers of cases could be included. Second, to compensate for the small sample size, this study did not separate the suicidal behavior into ideation, plan, and attempt, as presented in many epidemiological studies of suicidal behavior. Third, because an instrument for the diagnosis of SUDs did not apply in the 2008 Thai NMH Survey, legal substances, such as anxiolytics and sedatives, were not considered. In addition, the details on frequency, quantity, and abuse or dependent patterns were not assessed. Fourth, the generalization of present findings to other ethnic groups should be done with caution. The patterns of illicit drug use and suicidal behavior are relatively different among regions and ethnic groups. ${ }^{20}$ Common illicit drugs used in the present sample are kratom and (meth)amphetamines, which may be uncommon in many parts of the world. Kratom, Mitragyna speciosa Korth (Rubiaceae), is native to Thailand and many Southeast Asian countries. The leaves have been used for their opium- and coca-like effects to relieve fatigue and enhance tolerance to hard work. ${ }^{21}$ Lastly, a proportion of the present respondents might have underreported their illicit drug uses.

\section{Conclusion}

The present findings provide a more precise understanding of the associations between suicidal behavior and illicit drug use. The findings suggested that illicit drug users with mental or alcohol use disorders have an increased risk of suicide. In addition, they tend to support the coexisting relationship of suicide and illicit drug use in which mental and alcohol use disorders are key factors for the increased suicide risk. Taken together with previous findings that all suicide victims who have SUDs also have other mental disorders, ${ }^{12}$ health systems may need an integrated approach for substance use and mental disorders to prevent suicide in illicit drug users.

In conclusion, mental or alcohol use disorders found in illicit drug users actually increase the suicide risk. These findings support the coexisting relationship that mental and alcohol use disorders play a vital role in increasing the suicide risk in illicit drug users.

\section{Acknowledgments}

The Department of Mental Health, Ministry of Public Health conducted the 2008 Thai NMH Survey. This study was supported by grant 54-09-003 from the Integrated Community Addiction Management Program, Thai Health Promotion Foundation.

\section{Disclosure}

The authors report no conflict of interest in this work.

\section{References}

1. Harris E, Barraclough B. Excess mortality of mental disorder. $\mathrm{Br} J$ Psychiatry. 1998;173:11-53.

2. Nock MK, Hwang I, Sampson N, et al. Cross-national analysis of the associations among mental disorders and suicidal behavior: findings from the WHO World Mental Health Surveys. PLoS Med. 2009;6(8):e1000123.

3. Harris E, Barraclough B. Suicide as an outcome for mental disorders: A meta-analysis. Br J Psychiatry. 1997;170:205-228.

4. Kessler RC, Borges G, Walters EE. Prevalence of and risk factors for lifetime suicide attempts in the National Comorbidity Survey. Arch Gen Psychiatry. 1999;56(7):617-626.

5. Nock MK, Borges G, Bromet EJ, et al. Cross-national prevalence and risk factors for suicidal ideation, plans and attempts. Br J Psychiatry. 2008;192(2):98-105.

6. Husky MM, Guignard R, Beck F, Michel G. Risk behaviors, suicidal ideation and suicide attempts in a nationally representative French sample. J Affect Disord. 2013;151(3):1059-1065.

7. Bohnert AS, Roeder K, Ilgen MA. Unintentional overdose and suicide among substance users: a review of overlap and risk factors. Drug Alcohol Depend. 2010;110(3):183-192.

8. Christiansen E, Jensen BF. A nested case-control study of the risk of suicide attempts after discharge from psychiatric care: the role of co-morbid substance use disorder. Nord J Psychiatry. 2009;63(2):132-139.

9. Handley TE, Inder KJ, Kay-Lambkin FJ, et al. Contributors to suicidality in rural communities: beyond the effects of depression. BMC Psychiatry. 2012;12:105.

10. Regier DA, Farmer ME, Rae DS, et al. Comorbidity of mental disorders with alcohol and other drug abuse. Results from the Epidemiologic Catchment Area (ECA) Study. JAMA. 1990;264(19):2511-2518.

11. Bronisch T, Wittchen HU. Suicidal ideation and suicide attempts: Comorbidity with depression, anxiety disorders, and substance abuse disorders. Eur Arch Psychiatry Clin Neurosci. 1994;244(2):93-98.

12. Cheng AT. Mental illness and suicide. A case-control study in east Taiwan. Arch Gen Psychiatry. 1995;52(7):594-603.

13. Vijayakumar L, Kumar MS, Vijayakumar V. Substance use and suicide. Curr Opin Psychiatry. 2011;24(3):197-202.

14. Tong Y, Phillips MR. Cohort-specific risk of suicide for different mental disorders in China. Br J Psychiatry. 2010;196(6):467-473.

15. Borges G, Loera CR. Alcohol and drug use in suicidal behaviour. Curr Opin Psychiatry. 2010;23:195-204.

16. Junsirimongkol B, Kittirattanapaiboon $P$, Khamwongpin $M$, Chutha W, Kongsuk T, Leejongpermpoon J. The prevalence and psychiatric co-morbidity of alcohol use disorders in Thailand: National Epidemiological Survey 2008. Journal of Mental Health of Thailand. 2011;19: 88-102.

17. Srisurapanont M, Kittirattanapaiboon P, Likhitsathian S, Kongsuk T, Suttajit S, Junsirimongkol B. Patterns of alcohol dependence in Thai drinkers: a differential item functioning analysis of gender and age bias. Addict Behav. 2012;37(2):173-178.

18. Suttajit S, Kittirattanapaiboon P, Junsirimongkol B, Likhitsathian S, Srisurapanont M. Risks of major depressive disorder and anxiety disorders among Thais with alcohol use disorders and illicit drug use: findings from the 2008 Thai National Mental Health survey. Addict Behav. 2012;37(12):1395-1399. 
19. Kittirattanapaiboon $\mathrm{P}$, Khamwongpin $\mathrm{M}$. The validity of the Mini International Neuropsychiatric Interview (MINI) - Thai version. Journal of Mental Health of Thailand. 2005;13(3):126-136.

20. Schneider B, Kõlves K, Blettner M, Wetterling T, Schnabel A, Värnik A. Substance use disorders as risk factors for suicide in an Eastern and a Central European city (Tallinn and Frankfurt/Main). Psychiatry Res. 2009;165(3):263-272.
21. Maurer HH. Chemistry, pharmacology, and metabolism of emerging drugs of abuse. Ther Drug Monit. 2010;32(5):544-549.

\section{Publish your work in this journal}

Neuropsychiatric Disease and Treatment is an international, peerreviewed journal of clinical therapeutics and pharmacology focusing on concise rapid reporting of clinical or pre-clinical studies on a range of neuropsychiatric and neurological disorders. This journal is indexed on PubMed Central, the 'PsycINFO' database and CAS.
The manuscript management system is completely online and includes a very quick and fair peer-review system, which is all easy to use. Visit http://www.dovepress.com/testimonials.php to read real quotes from published authors.

Submit your manuscript here: http://www.dovepress.com/neuropsychiatric-disease-and-treatment-journal 